\title{
Effect of Nutrition Education and Dietary Counseling on the Prevalence of Anaemia among Adolescent Girls Belonging to Different Socioeconomic Background, Samastipur District, Bihar
}

\author{
Debjani Das*, Sunita Kumari and Usha singh
}
Department of Food and Nutrition, Dr. Rajendra Prasad Central Agricultural University, Samastipur, Pusa, Bihar, India
*Corresponding author

\section{A B S T R A C T}

Keywords

Adolescent girls, Aneamia, Nutrition education, Dietary counselling, Socioeconomic group

Article Info

Accepted:

12 December 2020 Available Online: 10 January 2021
Total 100 respondents were selected from Samastipur district of Bihar aged 15 to 19 years and divided into three socio-economic groups i.e. lower class, middle class and upper class. Nutrition intervention and counselling was given to respondents in different sessions. Their Pre and post haemoglobin level was recorded. The study resulted that before nutrition education and dietary counselling around 39 per cent of girls were non anaemic and 61 per cent of adolescent girls were suffering from anaemia but after nutrition intervention and counselling it was observed that overall 66 per cent of adolescent girls had normal haemoglobin level. It was also observed that girls from lower class background were more anaemic as compared to middle class and upper class family. In rural areas of Samastipur district of Bihar, adolescent girls were suffered from anaemia due to lower socio-economic background, poor nutrition education and dietary counselling. Proper nutrition intervention and counselling must address not only the problem of anaemia, but also in proper dietary habits and deficiencies of other micronutrients.

\section{Introduction}

The adolescent population in India (243 million) is highest in the world followed closely by china (207 million) (Dave et al., 2017). Adolescents estimated over 21.4 per cent of the India population (Nair et al., 2017). Worldwide, it is expected that the number of adolescents will reach 1.13 billion by 2025 (Hussain et al., 2015). Adolescent girls constitute the group of future mothers but their health get the minimum importance since several years as they were considered less vulnerable section compared to children and women. But in the last decade their health got little global attention. Anaemia is the widely prevalent micronutrient deficiency that affects 24.8 per cent of global population (Hassan et al., 2017). National family health survey-3 (NFHS-3), data revealed that the adolescent girls (15 to 19 years) suffered from anaemia which was 56 per cent (Kaur 2006) and among tribal adolescent girls, the prevalence of anaemia was observed 53-90 per cent (Dhingra 2011). 
According to the joint survey conducted by the UNICEF and Government of Bihar (2006), it was revealed that the prevalence of anaemia was highest (92 per cent) among adolescent girls. According to National Family Health Survey-4 (2015-2016), a total of 57 per cent for every group of women in Bihar have anaemia, included 1 per cent of girls affected by severe anaemia, 14 per cent of girls were moderate anaemia and 46 per cent was suffered from mild anaemia.

In Bihar, adolescent girls are suffering from serious health problem due to socio economic conditions, nutrition and gender discrimination. According to National Nutrition Monitoring Bureau (2003), in the rural area more than 40-50 per cent girls have been reported to be undernourished and iron deficiency anaemia is about 70 per cent (jayshree 2017).

Several recent studies have reported that adolescent girls from every corner of India particularly from rural areas had poor health status and the roots of this problem was found that most of the adolescents were not aware about proper dietary pattern and also lack of nutritional knowledge.

\section{Materials and Methods}

Total 100 respondents were selected aged 15 to 19 years and divided into three socioeconomic groups i.e. lower class, middle class and upper class by using of Kuppuswami socio economic status (SES) scale Performa modernized by Kumar et al.(2013) (Tool 1). 78 respondents from lower class family, 14 respondents from middle class family and 8 respondents from upper class family were selected for this present study. Haemoglobin level of selected adolescent girls was estimated using Sahli's method. For estimating haemoglobin concentration, finger tip of the respondents was washed using spirit and $0.02 \mathrm{cc}$ blood was taken in a pipette and mixed with $1.4 \mathrm{ml}$ of N/10 HCL. A brown colour solution was observed and then the solution was diluted with distilled $\mathrm{H}_{2} \mathrm{O}$ till it matched the standard brown glass tube of sahli's haemoglobinometer. The final volume was suggested to be the concentration of haemoglobin.

On the basis of haemoglobin level, selected respondents were divided in to four groups which was normal, mild, moderate and severe anaemic. (WHO, 2011) (Kaur et al., 2018)

\begin{tabular}{|c|c|}
\hline Hemoglobin level (g/dl) & $\begin{array}{c}\text { Severity of anaemia } \\
\text { based on hemoglobin } \\
\text { concentration }\end{array}$ \\
\hline$\geq 12$ & Non-anaemic \\
\hline $\mathbf{1 1 - 1 1 . 9}$ & Mild \\
\hline $\mathbf{8 - 1 0 . 9}$ & Moderate \\
\hline$<\mathbf{8}$ & Severe \\
\hline
\end{tabular}

Lectures, storytelling, drama and videos were used to deliver the nutrition intervention and the frequency of dietary counselling was once in a month. To find out the impact of nutrition knowledge of respondents pre and post test were conducted and scoring of each component was done on two points i.e. whether correct or incorrect. Right response was allocated with a score i.e. one while wrong response was given score zero. Total score obtained of each selected subject was summed up for each aspect separately. Percentage, frequency and mean \pm standard deviation were used to analyse the data for grades of anaemia among adolescent girls.

\section{Results and Discussion}

Data in (Table 1) It was found that before imparting nutrition education and counselling only 32.05 per cent of lower class girls had normal haemoglobin level and the prevalence of mild, moderate and severe anaemia among lower class girls was found to be 41.03 per cent, 23.08 per cent and 3.85 per cent 
respectively. After delivering nutrition education and counselling it was observed

that 58.97 per cent of adolescent girls had normal haemoglobin level.

Table.1 Effect of nutrition education and dietary counselling on the prevalence of anaemia among selected adolescent girls belonging to different socioeconomic group

\begin{tabular}{|c|c|c|c|c|c|c|}
\hline \multirow{2}{*}{$\begin{array}{c}\text { Categories of } \\
\text { anaemia with } \\
\text { haemoglobin level\# }\end{array}$} & \multicolumn{2}{|c|}{$\begin{array}{c}\text { Lower class } \\
n=78\end{array}$} & \multicolumn{2}{|c|}{$\begin{array}{c}\text { Middle class } \\
n=14\end{array}$} & \multicolumn{2}{|c|}{$\begin{array}{c}\begin{array}{c}\text { Upper class } \\
n=8\end{array} \\
\text { a }\end{array}$} \\
\hline & Pre test & Post test & Pre test & Post test & Pre test & Post test \\
\hline $\begin{array}{c}\text { Non-anaemic } \\
(\geq 12 \mathrm{~g} / \mathrm{dl})\end{array}$ & $\begin{array}{c}25 \\
(32.05)\end{array}$ & $\begin{array}{c}46 \\
(58.97)\end{array}$ & $\begin{array}{c}8 \\
(57.14)\end{array}$ & $\begin{array}{c}12 \\
(85.71)\end{array}$ & $\begin{array}{c}6 \\
(75)\end{array}$ & $\begin{array}{c}8 \\
(100.0)\end{array}$ \\
\hline \multicolumn{7}{|l|}{ Anaemic (<12 g/dl) } \\
\hline Mild $(11-11.9$ g/dl) & $\begin{array}{c}32 \\
(41.03)\end{array}$ & $\begin{array}{c}24 \\
(30.77)\end{array}$ & $\begin{array}{c}4 \\
(28.57)\end{array}$ & $\begin{array}{c}2 \\
(14.29)\end{array}$ & $\begin{array}{c}2 \\
(25)\end{array}$ & - \\
\hline $\begin{array}{c}\text { Moderate (8-10.9 } \\
\text { g/dl) }\end{array}$ & $\begin{array}{c}18 \\
(23.08)\end{array}$ & $\begin{array}{c}7 \\
(8.97)\end{array}$ & $\begin{array}{c}2 \\
(14.29)\end{array}$ & - & - & - \\
\hline Severe $\quad(\leq 8 \mathrm{~g} / \mathrm{dl})$ & $\begin{array}{c}3 \\
(3.85)\end{array}$ & $\begin{array}{c}1 \\
(1.28)\end{array}$ & - & - & - & - \\
\hline
\end{tabular}

\# WHO 2011 (Kaur et al .2018)

$\mathrm{n}$ - Indicates the number of respondents.

Figures in parentheses indicate per cent of reference value.

Fig.1 Comparison between pre and post test of prevalence of anaemia among respondents

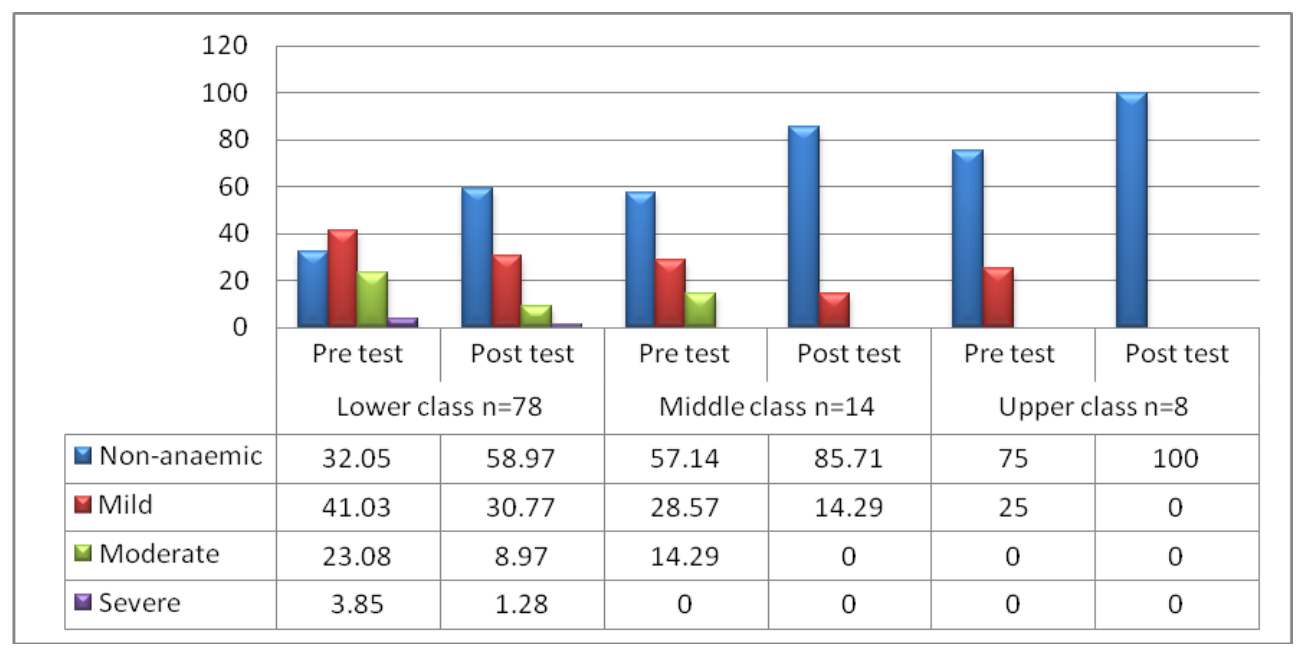

The prevalence of mild, moderate and severe anaemia in lower class girls were slightly decreased to 30.77 per cent, 8.97 per cent and 1.28 per cent respectively. In case of middle class family it was observed that before education and counselling 28.57 per cent girls suffered from mild anaemia and 14.29 per cent girls suffered from moderate anaemia but after delivering education none of the girls suffered from moderate anaemia. Around
57.14 per cent of middle class girls were non anaemic but after one month of instruction it was increased to 85.71 per cent. It was observed that before education around 25 per cent of upper class girls were adversely affected by mild anaemia and 75 per cent of girls had normal haemoglobin level but after education and dietary counselling it was observed that adolescent girls from upper class family totally recovered from anaemia. 
In conclusion the rural areas of Samastipur district of Bihar, adolescent girls were suffered from anaemia due to lower socioeconomic background, poor nutrition education and dietary counselling. Proper nutrition intervention and counselling must address not only the problem of anaemia, but also in proper dietary habits and deficiencies of other micronutrients.

\section{References}

Dave, H., Nimbalkar, S.M., Vasa, R. and Phatak, A.G. (2017). Assessment of Physical Activity among Adolescents: A Cross-sectional Study. Journal of Clinical and Diagnostic Research.11(11): SC21-SC24.

Dhingra, R. (2011). An assessment of health status of adolescent gujjar tribal girls of Jammu district.Studies of Tribes and Tribals.9(2):133-38.

Hussain, R A. and Kahn, P.S. (2015). Comparative study of the nutritional and health status among adolescent students (boys and girls) in rural area, Chandragiri, Chittoordistrict.A.P. IOSR Journal of Dental and Medical Sciences.14(9):30-37.

Jayashree.(2017). Food gap and nutritional insecurity among adolescent girls in rural community of Muzaffarpur district, Bihar. International Journal of
Home Science.3(2): 350-352.

Nair, A., Doibale, M.K., Kuril, B.M. and Domple, V.K. (2017).Study of nutritional status of adolescent girls in a rural area of a district of Maharashtra.International Journal of Community Medicine and Public Health.4(12):4617-4622.

Kaur, S (2006). Epidemiological correlates of nutritional anaemia adolescent girls of rural wardha.Indianjournal of community medicine ,31:255-258.

Kaur, S., Bains, K. and Kaur, H. (2018). Aneamia among school-going children in the perspective of socio-economic disparity in Panjab, India. Journal of Applied and Nutural Science. 10(1);230-235.

World Health Organization.(2001). The world health report reducing risk for promoting healthy life.Geneva.

World Health Organization.(2017) WHO methods and data sources for global burden of disease estimates 2000-2015. Geneva, http://www.who.int/healthinfo/global_b urden_disease/ GlobalDALYmethods_2000_2015.pdfaccessed 13 April 2018.)

World Health Organization www.searo.who.int

\section{How to cite this article:}

Debjani Das, Sunita Kumari and Usha singh. 2021. Effect of Nutrition Education and Dietary Counseling on the Prevalence of Anaemia among Adolescent Girls Belonging to Different Socioeconomic Background, Samastipur District, Bihar. Int.J.Curr.Microbiol.App.Sci. 10(01): 1085-1088. doi: https://doi.org/10.20546/ijcmas.2021.1001.131 